2018

\title{
Content of Qualitative Feedback Provided During Structured, Confidential Reference Checks
}

Cynthia A. Hedricks

SkillSurvey, Inc.

Disha Rupayana

SkillSurvey, Inc.

Leigh Puchalski

SkillSurvey, Inc.

Chet Robie

Wilfrid Laurier University

Follow this and additional works at: https://scholarworks.bgsu.edu/pad

Part of the Human Resources Management Commons, Industrial and Organizational Psychology Commons, and the Other Psychology Commons

How does access to this work benefit you? Let us know!

\section{Recommended Citation}

Hedricks, Cynthia A.; Rupayana, Disha; Puchalski, Leigh; and Robie, Chet (2018) "Content of Qualitative Feedback Provided During Structured, Confidential Reference Checks," Personnel Assessment and Decisions: Number 4 : Iss. 1 , Article 4. DOI: https://doi.org/10.25035/pad.2018.004

Available at: https://scholarworks.bgsu.edu/pad/vol4/iss1/4

This Main Article is brought to you for free and open access by the Journals at ScholarWorks@BGSU. It has been accepted for inclusion in Personnel Assessment and Decisions by an authorized editor of ScholarWorks@BGSU. 


\title{
Content of Qualitative Feedback Provided During Structured, Confidential Reference Checks
}

\author{
Cynthia A. Hedricks ${ }^{1}$, Disha Rupayana ${ }^{1}$, Leigh Puchalski ${ }^{1}$, and \\ Chet Robie ${ }^{2}$ \\ 1. SkillSurvey, Inc. \\ 2. Wilfrid Laurier University
}

ABSTRACT

\section{KEYWORDS}

reference checking, multirater assessment, qualitative, text analysis, narrative, natural language processing (NLP)

\begin{abstract}
The present study used text analytics software to examine the unstructured (or qualitative) data provided by job references during confidential, multirater reference checks. With respect to both work-related strengths and areas of improvement, job references more frequently provided words or short phrases relating to "soft skills" such as working with others and communication as opposed to "hard skills" such as computer programming or mathematics. Although some commonalities across jobs were found to exist, the frequency of identified categories for both work-related strengths and areas of improvement did differ across jobs.
\end{abstract}

The reference check is a selection tool in which potential employers request information from informants who are familiar with an applicant's behavior in an employment setting. The information can range from dates of employment, instances of misconduct or superlative performance, typical job performance, judgment of potential, or whether the prior employer would rehire the applicant. Informants are typically previous direct supervisors but could also be human resource representatives, coworkers, or customers. Reference checks are typically performed over the phone (Society for Human Resource Management, 2005) but could also be conducted via regular mail, email, or a cloudbased application.

The reference check as a selection tool has been relatively neglected in the research literature compared to other components of selection. A literature search of the PsychINFO database from the years 1900 to 2016 using the keywords in the document title "reference checks," "reference checking," or "reference check" yielded only five peer-reviewed, empirical articles. The low reported validity of the reference check may be a reason that researchers have neglected this tool (cf. Hunter \& Hunter, 1984, table 9). On the other hand, reference checking is a fairly ubiquitous phenomenon. One of the questions that Ryan, McFarland, Baron, and Page (1999) asked of employers in 20 countries was how often they "Contact previous employers by phone" on a scale from $1=$ never, 2 = rarely $(1-20 \%)$,
$3=$ occasionally $(21-50 \%), 4=$ often $(51-80 \%)$, and $5=$ almost always or always (81-100\%). The average and standard deviation of the response across countries was 3.60 and 1.41, respectively. However, employers in six countries (Australia, Canada, Ireland, New Zealand, South Africa, and Sweden) evidenced means over 4.00 and employers in the United States reported on average $3.94(S D=1.21)$. If we are to continue to use reference checking in selection, it is incumbent upon researchers and practitioners alike to search for ways to increase its utility.

This paper is organized in the following manner. First, we will discuss the typical objections to reference checking. Second, we will discuss several quantitative studies that have examined the reliability and validity of structured reference checks. ${ }^{1}$ Third, we will present specific research questions and describe the qualitative methodology we used to answer these questions. Finally, we will discuss the results of our study with particular attention to: (a) what personnel selection experts can take home in terms of ways to improve the value of reference checking, and (b) ways that future research can build upon these findings.

Corresponding author:

Cynthia A. Hedricks

Email: chedricks@skillsurvey.com

Phone: 609-751-3779

Address: 1235 Westlakes Drive, Suite 330

Berwyn, PA 19312 
Very little research has examined in a systematic manner the objections that exist for the process of reference checking. However, as practitioners we have encountered the following objections from various stakeholders; supporting references are provided where available. The first objection is that applicants are motivated to solicit references only from those individuals who will say positive things about them. Second, and relatedly, those who ultimately agree to act as references tend to predominantly say positive things about the applicant. This puts users of reference information in the difficult position of "reading the tea leaves," or as one practitioner source suggests, "looking for unspoken words" or hidden meanings from references (Babcock, 2008). A third objection is that references are afraid to say anything negative, such as work-related issues or potential areas for improvement, for fear of being sued for defamation (Ryan \& Laser, 1991; Woska, 2007). Fourth, applicants could provide false references (e.g., personal friends instead of previous supervisors or coworkers). Finally, and perhaps most perniciously, a perception exists that reference checks by their very nature cannot be reliable or valid. Several of us have been approached at professional conferences asking us why we are doing research in this area because everyone knows that reference checking is not useful or meaningful.

Several quantitative studies have examined the validity or reliability of structured reference checks. Hunter and Hunter (1984, table 9) provided a meta-analytic estimate based on 10 correlations of a mean validity (against job performance) of $r=.26$. Taylor, Pajo, Cheung, and Stringfield (2004) found that a structured telephone reference check was factorially differentiated and was predictive of performance for those in entry-level customer service jobs $(r=$ .25 uncorrected; $r=.36$ corrected for range restriction and criterion unreliability). Finally, Hedricks, Robie, and Oswald (2013) found acceptable levels of internal consistency, interrater reliability, and test-retest reliability of a structured, multirater reference check; support was also found for prediction of involuntary turnover.

It appears then that at least one objection to reference checking, that it inherently lacks reliability and validity, has at least been partially refuted by empirical research on the behavioral or quantitative ratings provided by multiple reference providers. Yet several of the objections to reference checking surround the general theme of only getting positive information from references. If organizations are only provided with positive information on job applicants, it is difficult to use the reference check to drive decisions.

1 Structured reference checking entails asking all references the same questions regarding the applicant's past work behavior and evaluating the responses to these questions in the same manner across applicants. Insofar as we will be dealing with structured reference checking in this paper, we will not be referring to more unstructured and related methods such as letters of recommendation (LORs).
It is suggested that qualitative methods can be used to explore the extent to which references provide information such as issues surrounding an applicant's work behavior or areas in which the applicant could improve at work. Structured reference checks often contain standardized questions with quantitative response options which are presented to the reference providers. However, there is typically a section that solicits unstructured responses. In the present study, the structured reference check contained a section that asked the applicant's references to comment in a narrative fashion on the individual's work-related strengths and areas for improvement. Qualitative methods could then be used to answer the following research questions:

R1: What percentage of the reference providers furnished narrative comments related to both the applicants' workrelated strengths and their areas for improvement?

R2: What were the applicants' top work-related strengths and areas for improvement?

R3: Were there similarities in the work-related strengths and areas for improvement across applicants applying for a variety of jobs?

R4: Were there differences in the work-related strengths and areas for improvement across applicants applying for a variety of jobs?

The first two research questions (R1, R2) address some very basic questions posed by those attempting to use reference check information during the hiring process. That is, will the majority of job references provide open-ended comments, and perhaps more specifically, will the comments focusing on areas of improvement relate to actionable behaviors in the workplace? To our knowledge, there has been no large-scale study of qualitative information provided during a reference check in order to determine: (a) reference response rates to open-ended questions, or (b) whether the comments would be related to work-related competence and other relevant behaviors. The remaining research questions (R3, R4) address whether there is a common set of top themes across a wide variety of jobs and reference providers, or whether the data from the reference providers indicate some unique strengths and areas for improvement at the job level. These latter questions are important so that practitioners can have some guidance on how much generalizability they can expect across jobs on the content of reference feedback.

We attempted to answer these questions using the following: a large dataset that includes multirater reference feedback for applicants applying for a wide variety of jobs across numerous industries and automated, text analytic software. Regardless of the outcome, at the very least, we expect the results to have implications for both personnel selection and workforce development. 


\section{METHOD}

Both quantitative (numeric ratings) and qualitative (text) data were collected using an automated (i.e., webbased) reference check system that delivers detailed, jobspecific feedback. The process was as follows: (a) an end user entered an applicant's contact information into the online system and selected a behavioral survey specific to the open position; (b) the applicant received an email generated by the system, whereupon they entered contact information on their professional job references (typically five); (c) references received a survey comprising approximately 26 behavioral items on a quantitative, seven-point Likert-type scale and two open-ended text boxes, one box in which to enter the applicant's top three work-related strengths, and another for entering their top three areas for improvement at work; (4) references had the option to complete and submit the confidential survey on the applicant's prior work behavior; and (5) a report on the applicant was available to the employer within approximately 2 days (on average). References were guaranteed confidentiality; their feedback was not associated with any part of their contact information. The overall average numeric (i.e., quantitative) ratings of the work behaviors were found to be psychometrically sound, legally compliant (e.g., did not show significant differences across demographic groups), and predictive of involuntary turnover and supervisor evaluations of performance (Hedricks, et al., 2013). ${ }^{2}$

The analytic approach taken towards the qualitative data in the present study followed the principles of content analysis (Krippendorff, 2013). We chose to use an empirically driven, inductive content analysis model (Stemler, 2015). Furthermore, a highly nonevaluative approach known as in vivo coding was utilized. In vivo coding (also known as "literal" or "verbatim" coding) is a coding method where the code refers to a word or short phrase from the actual language provided in the qualitative data (Saldaña, 2013). An empirically driven, inductive content analysis model using in vivo coding was chosen in the present study as there are no large-scale published studies on the nature or content of qualitative data provided by an applicant's references to guide, on an a priori basis, the use of a more emergent or theoretical framework.

The larger database contained feedback on applicants who were reference checked on one of 402 different jobspecific surveys; each survey was grouped into one of the five $\mathrm{O}^{*}$ NET Job Zones, ranging from Job Zone 1 (occupations that need little or no preparation) to Job Zone 5 (occupations that need extensive preparation; https://www.onetonline.org/help/online/zones). As analysis of qualitative data is highly time intensive, a representative sample of

2 More information on the system that generated the data can be found in Hedricks et al. (2013) on the bottom of pages 100 and 101 and in notes 2 and 3 on p. 109. surveys was selected for study (see Table 1 for survey list). Specifically, within each O*NET Job Zone, data from surveys met the following criteria: (a) at least 250 applicants were reference checked on the survey; (b) no one potential employer contributed more than $10 \%$ of the surveys; (c) no one industry contributed more than $25 \%$ of the surveys (with the exception of surveys for jobs in healthcare), and (d) jobs differed in the type of work generally performed (i.e., only one of many customer service surveys was used).

TABLE 1.

List of the 25 Job-Specific Surveys

\begin{tabular}{|l|}
\hline Accountant \\
\hline Administrative professional \\
\hline Childcare worker \\
\hline Customer and sales representative-phone (call center) \\
\hline Electrical engineer \\
\hline Faculty \\
\hline Financial controller \\
\hline Food server \\
\hline Hospital environmental services \\
\hline Housekeeper \\
\hline Human resources director \\
\hline Information technology, entry-level \\
\hline Nursing manager/director \\
\hline Physician \\
\hline Project manager \\
\hline Registered nurse, entry-level \\
\hline Registered nurse \\
\hline Retail cashier \\
\hline Sales-field \\
\hline Security officer \\
\hline Skilled trades worker \\
\hline Software developer \\
\hline Store manager \\
\hline Truck driver \\
\hline Warehouse order selector \\
\hline
\end{tabular}


The surveys thus chosen were representative of jobs across a wide range of industries, companies, and levels of experience, education, training, and responsibility (i.e., hourly, entry-level professional, experienced individual contributor, managerial, or executive).

We used a stratified sampling approach. Stratified sampling refers to a type of sampling method that divides the population into separate groups called strata; probability samples (in our case simple random samples) are then drawn from each strata (Särndal, Swensson, \& Wretman, 1992). The strata in our case was job-specific survey. A sample of 200 applicants for each of the 25 different surveys (thus $200 \times 25=5,000$ total applicants) was randomly chosen from a larger sample of all applicants who had received quantitative, behavioral survey responses from at least two managers and at least two nonmanagers. These 5,000 applicants were applying for a job in one of 34 different industries, represented by 636 different companies. Most applicants $(85.8 \%$ for gender, $84.4 \%$ for age, and $84.3 \%$ for ethnicity) provided responses to optional demographic questions, revealing a sample composition of $52.6 \%$ female, $62.5 \%$ under 40 years of age, and $61.6 \%$ White.

Based on the representativeness of the sample, the large amount of qualitative data retrieved and analyzed, and a comparison to typical sample sizes in qualitative research, it is estimated that there was an adequate level of saturation (i.e., the level of sampling upon which more data will not lead to more information related to our research questions; Bowen, 2008; Sandelowski, 1995).

A total of 25,667 references provided quantitative, behavioral ratings on one of these 5,000 applicants. Data from two managers and two coworkers per applicant were randomly chosen for text analysis, yielding a sample of data from 20,000 job references ( 25 surveys x 200 applicants $\times$ 4 references per applicant).

Given the volume of qualitative data and scope of the project, analyses were automated with $\mathrm{IBM}^{\circledR}$ SPSS ${ }^{\circledR}$ Text Analytics for Surveys, v4.0.1 (IBM, 2011), software that uses a combination of linguistic resources and statistical techniques. It was first used to access and download the qualitative data from the online reference check system. There were two separate files of qualitative data, one for the applicant's work-related strengths and the other for their areas for improvement. Prior to text analytic coding, the following information was deleted from the data files for both applicants and references: first and last names, demographic information, contact information, and company names.

Within each of these files, at the level of the individual job reference, the software was used to identify and code or "extract" words (e.g., communication; experience; commitment) and short phrases (e.g., accepting feedback; working with others). The software was also used to extract short phrases containing modifiers that were not describing a particular work behavior (e.g., he is "great") as well as short phrases that appeared in the text box for areas for improvement yet included the words "great" or "excellent" (e.g., she is a great communicator or he is excellent at communicating). ${ }^{3}$ The software was also used to extract words that were dictionary-based synonyms (e.g., accepting feedback as well as receiving feedback). We coded only the words (or short phrases) used by the reference provider, using dictionary synonyms to group like terms. It is important to note that a single sentence written by a job reference could result in multiple words or short phrases to be coded. To establish interrater reliability, three independent raters were assigned 50 random comments to categorize; these comments had already been coded using the software. The raters were instructed to extract words and short-phrases that occurred in these comments and to categorize them into themes. Overall, there was $90 \%$ interrater reliability. More specifically, the four raters had $100 \%$ agreement on the coding of 45 of the 50 items. On the remaining five items, disagreement was low: 3 of the 4 raters (75\%) agreed on the extraction and categorization of the words/short-phrases. Due to the low level of disagreement, these categorizations were not changed.

As a result of the coding process described above, ${ }^{4} 190$ themes were identified: 80 were common to both strengths and areas for improvement; two were unique to strengths; and 23 were unique to areas for improvement. Fifty-two additional themes in the areas for improvement were work behaviors preceded by the modifier "great" or "excellent," as described above. Thirty-three themes where the words "too much" were used as modifiers were also identified. For descriptive purposes, the most frequently occurring word/short phrase extracted was used to name the theme (e.g., communication; leadership). The software identified (true, false) whether the job a reference provided at least one word/short phrase for each theme. Upon export to IBM ${ }^{\circledR}$ SPSS ${ }^{\circledR}$ Statistics v.23, a "true" was converted to a " 1 ," and a "false" was converted to a " 0. ." Each of the two files (strengths; areas for improvement) contained 20,000 cases, one for each reference, as well as a column for each

3 For $62.4 \%$ of applicants, at least one reference provided a behavior in areas for improvement that was preceded by "great" or "excellent." However, in $98.1 \%$ of these occurrences, references also provided a behavior that was not preceded by "great" or "excellent." Ex: Does great analyses that are backed up with great oral presentations, but written summaries could be better.

4 Only dictionary synonyms were combined into common categories; there was no aggregation of categories. "No text provided" describes instances where the reference did not enter any text into the open-ended text box. "Can't think of anything" is a category formed from instances where the reference wrote the phrase "I can't think of anything" into the open-ended text box. 
of the 190 themes.

Feedback was collapsed across references to analyze the data at the applicant level, as this is the level at which the end users (e.g., recruiters and hiring managers) receive and use the data. For overall (across job-specific survey) analyses, we present: (a) the percentage of applicants with at least one reference providing a given word/short phrase/ response pattern; and (b) means and standard deviations across references. For example, a mean of 0.23 signifies that, on average across applicants, almost one in four references provided a given word/short phrase/response pattern. We did not provide means and standard deviations for the job-specific survey results to simplify presentation. It should be noted that in the vast majority of the cases, the rank order of incidences of a given word/short phrase/response pattern did not differ when using percentages versus means.

\section{RESULTS AND DISCUSSION}

Most references provided text for the applicant's strengths and areas for improvement $(88.9 \%$ and $82.2 \%$, respectively). Across all themes for both strengths and areas for improvement, there were 83,786 words/short phrases/ response patterns ${ }^{5}$ identified $(49,458$ and 34,328 , respectively). This finding answers our first research question, R1: What percentage of reference providers furnished narrative comments related to both the applicants' work-related strengths and areas for improvement? The overwhelming majority of reference providers will furnish narrative comments related to an applicant's strengths and areas for improvement.

The remaining research questions are addressed with data that were collapsed at the level of the applicant, as described in the Methods. Our second research question was, R2: What were the applicants' top work-related strengths and areas for improvement? The top 10 workrelated strengths across all job-specific surveys are listed in Table 2 and comprise (in descending order): commitment/ dedication; dependable/reliable/meets deadlines; team orientation; no text provided; attention to detail/accuracy; attitude/energy; communication; punctuality/attendance; professionalism; and honesty/trustworthiness. The top 10 areas for improvement at work across all job-specific surveys are listed in Table 3 and comprise (in descending order): no text provided; great/excellent; communication; confidence/assertiveness, can't think of anything/no improvement needed; knowledge; experience; great/excellent commitment/ dedication; time management/prioritizing; and workaholic/ works too much.

5 There were two response patterns: one was the lack of any text provided in the open-ended text box; the other was on rare occasions when the response was noncodable (e.g., continue to improve on strengths as well as their weakness).
One of the most compelling findings from our study was the emergence of the theme of communication in both top-10 lists. Competence in interpersonal communication has been a neglected area of research in the organizational sciences. We could only find one fairly recent published citation in the peer-reviewed literature that examined the relationship between competence in interpersonal communication and job performance (Payne, 2005). It is likely that this competence is a complex, multidimensional, and multilevel phenomenon. As noted by Phillips (1984), defining the construct of interpersonal communication competence is like "climbing a greased pole" (p. 25). It is therefore not surprising that "communication" has not been directly studied in organizational contexts to a great degree even if identified by reference providers as a top concern.

It is also interesting to note that categories related to the oft-cited generalizable work-related construct of conscientiousness were found in both top 10 lists. Themes related to the constructs of commitment and dedication were found in both lists. The themes of dependable/reliable/meets deadlines; attention to detail/accuracy; and punctuality/attendance were found in the list of top work-related strengths. This finding suggests that the presence (or absence) of conscientiousness-type behaviors is not only readily observed by others but also that presence (or absence) of these behaviors is salient or important enough to mention when references are providing open-ended feedback. It is perhaps not surprising that conscientiousness-type behaviors are so well represented in the top 10 lists in our study. Conscientiousness has been found to predict job performance across many occupations (cf. Barrick, Mount, \& Judge, 2001).

The finding of workaholic/works too much as a category in work-related areas for improvement is consistent with research reporting curvilinear effects between personality traits and job performance (Le et al., 2011). In fact, Pierce and Aguinis (2013) provide evidence to suggest that this "too-much-of-a-good-thing" (TMGT) effect is pervasive across levels of analysis (i.e., micro to macro) and management subfields (e.g., organizational behavior, strategic management). The finding of this theme in our study bolsters the supposition of the pervasiveness of the TMGT effect.

Burrus, Jackson, Xi, and Steinberg (2013) conducted a recent study using job-analytic ratings to examine the most important competencies for college graduates to succeed in the 21 st century. The competencies that stood out as important across jobs in their study were problem solving, fluid intelligence, teamwork, achievement/innovation, and communication skills. Arguably, achievement/innovation could be matched with our category of commitment/dedication/hard worker. Thus, three of the five competencies that Burrus et al. (2013) found to be critical for the 21 st century workforce were echoed in our findings.

In sum, examining both Tables 2 and 3 gives one an appreciation for the role of "soft skills" (Laker \& Powell, 
TABLE 2.

Top 10 Work-Related Strengths Across All Job-Specific Surveys

\begin{tabular}{|c|c|c|c|c|}
\hline Category & Direct quote from reference & $\%$ & $M$ & $S D$ \\
\hline $\begin{array}{l}\text { Commitment/dedication/ } \\
\text { hard worker }\end{array}$ & $\begin{array}{l}\text { "has many strengths, but the top } 3 \text { would } \\
\text { be commitment/dedication to this job" }\end{array}$ & 61.70 & 0.23 & 0.22 \\
\hline $\begin{array}{l}\text { Dependable/reliable/meets } \\
\text { deadlines }\end{array}$ & "Reliable, dependable, shows up on time" & 45.30 & 0.15 & 0.19 \\
\hline Team orientation & $\begin{array}{l}\text { "Team oriented...went above and beyond } \\
\text { to help out associates that were falling } \\
\text { behind, when his tasks were done" }\end{array}$ & 38.84 & 0.12 & 0.17 \\
\hline No text provided & & 34.60 & 0.11 & 0.17 \\
\hline $\begin{array}{l}\text { Attention to Detail/ } \\
\text { Accuracy }\end{array}$ & $\begin{array}{l}\text { "High level of accuracy and attention to } \\
\text { detail" }\end{array}$ & 32.36 & 0.10 & 0.16 \\
\hline Attitude/energy & $\begin{array}{l}\text { "will complete any task given to the best } \\
\text { of their ability with a positive attitude" }\end{array}$ & 32.04 & 0.10 & 0.15 \\
\hline Communication & $\begin{array}{l}\text { "Communication - excellent } \\
\text { communicator; listens as well as explains" }\end{array}$ & 26.58 & 0.08 & 0.14 \\
\hline Punctuality/attendance & $\begin{array}{l}\text { "During the years I worked with ... I } \\
\text { found him to be professional, reliable, and } \\
\text { extremely punctual" }\end{array}$ & 26.40 & 0.08 & 0.15 \\
\hline Professionalism & $\begin{array}{l}\text { "She remains professional and polished } \\
\text { under any circumstance" }\end{array}$ & 26.22 & 0.08 & 0.14 \\
\hline Honesty/trustworthiness & $\begin{array}{l}\text { "is a very quiet and trustworthy person. } \\
\text { Honesty and dedication to what they do } \\
\text { sums up their strengths" }\end{array}$ & 24.80 & 0.07 & 0.14 \\
\hline
\end{tabular}

Note. $N=5,000$ job applicants from 25 surveys. $\%=$ percentage of applicants with at least one reference providing word/ short phrase/response pattern.

2011) in the hiring process. Most categories on both lists assess skills related to self-regulation or interpersonal acumen that are not necessarily job specific, yet they are clearly important to those who have worked with the applicants in the past. This suggests that using hiring strategies that focus solely on intellectual capability, previous job titles, and technical skills would be ignoring a potentially large portion of what job references perceive as important for successful job performance. This is an important finding as some well-known academics have voiced concern over the overall usefulness of non-cognitive self-report measures for use in personnel selection (Morgeson et al., 2007). Structured, confidential reference checks can thus tap into these noncognitive factors without resorting to problematic selfreports.

Negative information has been suggested to be more useful with respect to learning and future survival than positive information (Hanson, 2013); therefore, feedback on the applicant's work-related areas of improvement might be extremely useful to those making hiring decisions. However, no text provided was the most frequently occurring response pattern in this category of feedback. Also, job references provided significantly fewer work-related areas for improvement compared to work-related strengths. We posit several reasons for these findings. First, although job references were informed that their feedback on applicants was confidential, some may have perceived a risk of being accused of defaming an applicant and thus may not have felt comfortable providing information that may be perceived as negative, even though most U.S. states offer conditional or qualified privilege to job references when they make factual statements during a reference check (Gatewood, Feild, \& Barrick, 2015). Second, delivering negative feedback is not a desirable task (Baron, 1993) and many times actively avoided (Meyer, 1991). It is particularly surprising, then, how many work-related areas for improvement were identi- 
TABLE 3 .

Top 10 Areas for Improvement at Work Across All Job-Specific Surveys

\begin{tabular}{|c|c|c|c|c|}
\hline Category & Direct quote from reference & $\%$ & $M$ & $S D$ \\
\hline No text provided & & 51.24 & 0.18 & 0.21 \\
\hline Great/excellent & "was a great asset to the team." & 41.66 & 0.13 & 0.18 \\
\hline Communication & $\begin{array}{l}\text { "Better communication with their manager } \\
\text { as to what they are working on." }\end{array}$ & 24.46 & 0.07 & 0.13 \\
\hline Confidence/assertiveness & $\begin{array}{l}\text { "Improve confidence in delivering options } \\
\text { or presenting ideas" }\end{array}$ & 22.42 & 0.07 & 0.14 \\
\hline $\begin{array}{l}\text { Can't Think of Anything/No } \\
\text { Improvement Needed }\end{array}$ & $\begin{array}{l}\text { "is a great employee. I can't think of } \\
\text { anything major to improve." }\end{array}$ & 20.64 & 0.06 & 0.13 \\
\hline Knowledge & "Knowledge in contract management" & 15.96 & 0.04 & 0.11 \\
\hline Experience & $\begin{array}{l}\text { "Continue to broaden their engineering } \\
\text { experience" }\end{array}$ & 15.36 & 0.05 & 0.11 \\
\hline $\begin{array}{l}\text { Great/excellent } \\
\text { commitment/dedication }\end{array}$ & $\begin{array}{l}\text { "is a dedicated hard worker and always } \\
\text { stepped up to the task at hand" }\end{array}$ & 15.06 & 0.04 & 0.10 \\
\hline $\begin{array}{l}\text { Time management/ } \\
\text { prioritizing }\end{array}$ & $\begin{array}{l}\text { "Time management under extremely short } \\
\text { deadlines." }\end{array}$ & 14.80 & 0.04 & 0.10 \\
\hline Workaholic/works too much & $\begin{array}{l}\text { "Can sometimes take on too much work to } \\
\text { please managers. Can become overloaded } \\
\text { over time when this occurs." }\end{array}$ & 12.96 & 0.04 & 0.09 \\
\hline
\end{tabular}

Note. $N=5,000$ job applicants from 25 surveys. $\%=$ percentage of applicants with at least one reference providing word/ short phrase/response pattern.

fied in this study; specifically, 188 themes were provided. Furthermore, the majority $(82 \%)$ of job references provided at least one work-related area for improvement. These findings are in contrast to earlier research that shows very little such information in more unstructured methods such as LORs (Grote, Robiner, \& Haut, 2001). We speculate that the confidential nature of the online process may lead to job references being more open and frank in their feedback compared to nonconfidential processes (Ceci \& Peters, 1984).

Our third research question was, R3: Were there similarities in the work-related strengths and areas for improvement across applicants applying for a variety of jobs? Our fourth research question was, R4: Were there differences in the work-related strengths and areas for improvement across applicants applying for a variety of jobs? The job-specific survey results are organized into five categories by the education, experience, and on-the-job training required for the position $\left(\mathrm{O}^{*}\right.$ NET Job Zone - see https://www.onetonline.org/help/online/zones) and can be found in a table in the appendix. What is immediately apparent from perusal of this table is that commonalities do exist for certain categories across jobs (e.g., commitment/ dedication/hard worker; and dependable/reliable/meets deadlines as work-related strengths, and communication as areas for improvement). However, considerable differences exist across jobs in terms of which categories appear in the "top five." These qualitative findings are consistent with quantitative findings that soft skills (e.g., personality) tend to vary in their importance across jobs. For example, Extraversion tends to predict job performance well for occupations involving social interaction (Barrick \& Mount, 1991).

\section{Implications for Personnel Selection Experts}

Several "take home" messages for personnel selection experts can be derived from this and past research in the area of reference checking. First, when structured and quantitative ratings are used, reference checks can be both reliable and valid for use in predicting performance and involuntary turnover for job applicants (Hedricks et al., 2013; Taylor et al., 2004). Second, contrary to conventional wisdom, when given an opportunity to provide narrative 
information on job applicants in a setting where they are guaranteed confidentiality, reference providers typically furnish job-related, actionable comments related to job applicants' strengths and areas for improvement. Reference checking should thus be seen as less of a "check" or desultory task that simply needs to be completed and more of a selection tool that should be conducted with care and prudence, and which will thus provide critical value in the hiring process.

\section{Areas for Future Research}

Several additional areas for future research appear fruitful. First, although the present study included a representative sample of jobs, it would be interesting to see whether the categories identified as most frequent generalize to additional jobs and job families. Second, as numbers $(0,1)$ were assigned to the qualitative data in this study, a mixed methods approach called "quantitizing" (Sandelowski, Voils, \& Knafl, 2009) could be used to examine the relationship of the quantitized variables to outcome variables such as hiring decisions, job performance, and turnover. Third, differences between managers and coworkers could be investigated in terms of the quantity and type of feedback they provided. Fourth, future research could examine, either in laboratory or field settings, what kinds of interventions in the reference collection process could elicit even more areas for improvement from reference providers. Fifth, we have largely framed our results from a personnel selection perspective. However, the results of this study have implications for education and workforce development. Research on how one shares results of this type with educators and whether these results can influence training or education at the secondary or postsecondary levels would be potentially fruitful.

\section{Conclusion}

The present study has shown that, with the aid of text analytic software, frequent words and short phrases can be identified and extracted from large samples of qualitative feedback on job applicants, such as those provided during structured, multirater, confidential reference checks. Furthermore, these words and short phrases can be categorized to provide insight into what job references think are the most frequent areas of work-related strengths and areas for improvement. Although some commonalities across jobs were found to exist, the frequency of identified categories for both work-related strengths and areas of improvement did differ across jobs.

\section{REFERENCES}

Babcock, P. (2008, March). It takes more than a reference check to weed out liars. HR News. https://www.shrm.org/hr-today/ news/hr-news/pages/story3_5.aspx

Baron, R. A. (1993). Criticism (informal negative feedback) as a source of perceived unfairness in organizations: Effects, mechanisms, and countermeasures. In R. Cropanzano (Ed.), Justice in the workplace (pp. 155-170). Hillsdale, NJ: Lawrence Erlbaum Associates.

Barrick, M. R., \& Mount, M. K. (1991). The Big Five personality dimensions and job performance: A meta-analysis. Personnel Psychology, 44, 1-26. doi: 10.1111/j.1744-6570.1991. tb00688.x

Barrick, M. R., Mount, M. K., \& Judge, T. A. (2001). Personality and performance at the beginning of the new millennium: What do we know and where do we go next? International Journal of Selection and Assessment, 9(1-2), 9-30. doi: 10.1111/1468-2389.00160

Bowen, G. A. (2008). Naturalistic inquiry and the saturation concept: A research note. Qualitative Research, 8(1), 137-152. doi: 10.1177/1468794107085301

Burrus, J., Jackson, T., Xi, N., \& Steinberg, J. (2013). Identifying the most important 21 st century workforce competencies: An analysis of the Occupational Information Network (O*NET). Princeton, NJ: Educational Testing Service.

Ceci, S. J., \& Peters, D. (1984). Letters of reference: A naturalistic study of the effects of confidentiality. American Psychologist, 39(1), 29-31.

Gatewood, R. D., Feild, H. S., \& Barrick, M. (2015). Human resource selection (8th edition). Mason, $\mathrm{OH}$ : Thomson SouthWestern.

Grote, C. L., Robiner, W. N., \& Haut, A. (2001). Disclosure of negative information in letters of recommendation: Writers' intentions and readers' experiences. Professional Psychology: Research and Practice, 32(6), 655-661. doi: 10.1037//07357028.32.6.655

Hanson, R. (2013). Hardwiring happiness: The new brain science of contentment, calm, and confidence. New York, NY: Harmony Books.

Hedricks, C. A., Robie, C., \& Oswald, F. L. (2013). Web-based multisource reference checking: An investigation of psychometric integrity and applied benefits. International Journal of Selection and Assessment, 21(1), 99-110. doi: 10.1111/ ijsa. 12020

Hunter, J. E., \& Hunter, R. F. (1984). Validity and utility of alternative predictors of job performance. Psychological Bulletin, 96(1), 72-98. doi: 10.1037/0033-2909.96.1.72

IBM. (2011). IBM SPSS Text Analytics for Surveys 4.0.1 User's Guide. Chicago, IL: IBM. 
Krippendorff, K. (2013). Content analysis: An introduction to its methodology (3rd ed.). Los Angeles, CA: Sage.

Laker, D. R., \& Powell, J. L. (2011). The differences between hard and soft skills and their relative impact on training transfer. Human Resource Development Quarterly, 22(1), 111-122. doi: $10.1002 /$ hrdq. 20063

Le, H., In-Sue, O., Robbins, S. B., Illies, R., Holland, E., \& Westrick, P. (2011). Too much of a good thing: Curvilinear relationships between personality traits and job performance. Journal of Applied Psychology, 96(1), 113-133. doi: 10.1037/a0021016

Meyer, H. H. (1991). A solution to the performance appraisal feedback enigma. Academy of Management Executive, 5, 68-76. doi: 10.5465/AME.1991.4274724

Morgeson, F. P., Campion, M. A., Dipboye, R. L., Hollenbeck, J. R., Murphy, K., \& Schmitt, N. (2007). Reconsidering the use of personality tests in personnel selection. Personnel Psychology, 60, 683-729. doi: 10.1111/j.1744-6570.2007.00089.x

Payne, H. J. (2005). Reconceptualizing social skills in organizations: Exploring the relationship between communication competence, job performance, and supervisory roles. Journal of Leadership and Organizational Studies, 11(2), 63-77. doi: $10.1177 / 107179190501100207$

Phillips, G. M. (1984). A competent view of "competence." Communication Education, 33, 25-36. doi: $10.1080 / 03634528409384714$

Pierce, J. R., \& Aguinis, H. (2013). The too-much-of-a-good-thing effect in management. Journal of Management, 39(2), 313338. doi: $10.1177 / 0149206311410060$

Ryan, A. M., \& Laser, M. (1991). Negligent hiring and defamation: Areas of liability related to pre-employment inquiries. Personnel Psychology, 44(2), 293-319. doi: 10.1111/j.17446570.1991.tb00960.x
Ryan, A. M., McFarland, L., Baron, H., \& Page, R. (1999). An international look at selection practices: Nation and culture as explanations for variability in practice. Personnel Psychology, 52, 359-391. doi: 10.1111/j.1744-6750.1999.tb00165.x

Saldaña, J. (2013). The coding manual for qualitative researchers (2nd edition). Los Angeles, CA: Sage.

Sandelowski, M. (1995). Sample size in qualitative research. Research in Nursing \& Health, 18, 179-183. doi: 10.1002/ nur.4770180211

Sandelowski, M., Voils, C. I., \& Knafl, G. (2009). On quantitizing. Journal of Mixed Methods Research, 3(3), 208-222. doi: $10.1177 / 1558689809334210$

Särndal, C., Swensson, B., \& Wretman, J. (1992). Model assisted survey sampling. New York, NY: Springer-Verlag.

Society for Human Resource Management. (2005). 2004 reference and background checking survey report. Alexandria, VA: Society for Human Resource Management.

Stemler, S. E. (2015). Content analysis. In R. Scott \& S. Kosslyn (Eds.), Emerging trends in the social and behavioral sciences (pp. 1-14). doi: 10.1002/9781118900772.etrds0053

Taylor, P. J., Pajo, K., Cheung, G. W., \& Stringfield, P. (2004). Dimensionality and validity of a structured telephone reference check procedure. Personnel Psychology, 57, 745-772. doi: 10.1111/j.1744-6750.2004.00006.x

Woska, W. J. (2007). Legal issues for HR professionals: Reference checking/background investigations. Public Personnel Management, 36(1), 79-89. doi: 10.1177/009102600703600106

RECEIVED 06/09/17 ACCEPTED 03/09/18 
Appendix

Top Five Work-Related Strengths and Top Five Areas for Improvement (AIs) Within Job-Specific Surveys

\begin{tabular}{|c|c|c|c|}
\hline \multicolumn{4}{|c|}{ O*NET Job Zone 1} \\
\hline Top five categories (strengths) & $\%$ strengths & Top five categories (AIs) & $\%$ AIs \\
\hline \multicolumn{4}{|c|}{ Food server } \\
\hline Commitment/dedication/hard worker & 61.00 & Great/excellent & 48.50 \\
\hline Dependable/reliable/meets deadlines & 58.50 & Text not provided & 48.50 \\
\hline Customer service & 46.00 & $\begin{array}{l}\text { Can't think of anything/no improvement } \\
\text { needed }\end{array}$ & 31.50 \\
\hline Punctuality/attendance & 45.00 & Communication & 24.00 \\
\hline Friendly/outgoing & 40.50 & Confidence/assertiveness & 20.00 \\
\hline \multicolumn{4}{|c|}{ Housekeeper } \\
\hline Commitment/dedication/hard worker & 67.00 & Great/excellent & 47.50 \\
\hline Dependable/reliable/meets deadlines & 60.00 & Text not provided & 46.50 \\
\hline Punctuality/attendance & 50.00 & $\begin{array}{l}\text { Can't think of anything/no improvement } \\
\text { needed }\end{array}$ & 40.50 \\
\hline No text provided & 39.00 & Communication & 27.50 \\
\hline Attitude/energy & 38.00 & Great/excellent commitment/dedication & 23.50 \\
\hline \multicolumn{4}{|c|}{ Hospital environmental services } \\
\hline Commitment/dedication/hard worker & 70.00 & Text not provided & 49.00 \\
\hline Punctuality/attendance & 58.50 & Great/excellent & 45.00 \\
\hline Team orientation & 52.50 & $\begin{array}{l}\text { Can't think of anything/no improvement } \\
\text { needed }\end{array}$ & 43.00 \\
\hline Dependable/reliable/meets deadlines & 47.50 & Communication & 29.50 \\
\hline Attitude/energy & 47.00 & Great/excellent commitment/dedication & 28.00 \\
\hline \multicolumn{4}{|c|}{ Retail cashier } \\
\hline Dependable/reliable/meets deadlines & 55.00 & Text not provided & 50.00 \\
\hline Commitment/dedication/hard worker & 52.00 & Great/excellent & 49.00 \\
\hline Customer service & 46.50 & Confidence/assertiveness & 28.00 \\
\hline No text provided & 38.00 & Communication & 24.00 \\
\hline Friendly/outgoing & 35.00 & Great/excellent commitment/dedication & 16.00 \\
\hline \multicolumn{4}{|c|}{ Warehouse order selector } \\
\hline Commitment/dedication/hard worker & 65.50 & Text not provided & 60.50 \\
\hline Dependable/reliable/meets deadlines & 64.00 & Great/excellent & 44.00 \\
\hline No text provided & 50.50 & $\begin{array}{l}\text { Can't think of anything/no improvement } \\
\text { needed }\end{array}$ & 38.50 \\
\hline Punctuality/attendance & 48.00 & Confidence/assertiveness & 23.50 \\
\hline Team orientation & 41.50 & Communication & 22.50 \\
\hline
\end{tabular}




\begin{tabular}{|c|c|c|c|}
\hline \multicolumn{4}{|c|}{ O*NET Job Zone 2} \\
\hline Top five categories (strengths) & $\%$ strengths & Top five categories (AIs) & $\%$ AIs \\
\hline \multicolumn{4}{|c|}{ Administrative professional } \\
\hline Commitment/dedication/hard worker & 60.50 & Text not provided & 54.50 \\
\hline Dependable/reliable/meets deadlines & 60.50 & Great/excellent & 50.50 \\
\hline Organization skills & 46.50 & Confidence/assertiveness & 34.50 \\
\hline Attention to detail/accuracy & 42.00 & Communication & 20.00 \\
\hline Team orientation & 39.00 & Time management/prioritizing & 17.50 \\
\hline \multicolumn{4}{|c|}{ Childcare worker } \\
\hline Dependable/reliable/meets deadlines & 62.50 & Text not provided & 54.00 \\
\hline Commitment/dedication/hard worker & 59.00 & Great/excellent & 40.50 \\
\hline Compassionate/caring & 44.50 & Confidence/assertiveness & 29.50 \\
\hline Attitude/energy & 42.50 & $\begin{array}{l}\text { Can't think of anything/no improvement } \\
\text { needed }\end{array}$ & 28.50 \\
\hline No text provided & 37.50 & Communication & 27.00 \\
\hline \multicolumn{4}{|c|}{ Customer and sales representative-phone (call center) } \\
\hline Customer service & 56.50 & Text not provided & 60.00 \\
\hline Commitment/dedication/hard worker & 53.50 & Great/excellent & 44.50 \\
\hline Dependable/reliable/meets deadlines & 49.00 & Confidence/assertiveness & 26.50 \\
\hline No text provided & 39.00 & Communication & 23.50 \\
\hline Attitude/energy & 33.50 & Accepting feedback/criticism & 17.00 \\
\hline \multicolumn{4}{|c|}{ Security officer } \\
\hline Dependable/reliable/meets deadlines & 60.50 & Text not provided & 49.00 \\
\hline Commitment/dedication/hard worker & 53.50 & $\begin{array}{l}\text { Can't think of anything/no improvement } \\
\text { needed }\end{array}$ & 41.00 \\
\hline Punctuality/attendance & 37.00 & Great/excellent & 37.00 \\
\hline Professionalism & 36.00 & Communication & 22.50 \\
\hline Team orientation & 35.50 & Computer/tech skills & 17.50 \\
\hline \multicolumn{4}{|c|}{ Truck driver } \\
\hline Commitment/dedication/hard worker & 72.50 & Text not provided & 58.00 \\
\hline Dependable/reliable/meets deadlines & 68.50 & Great/excellent & 53.00 \\
\hline Punctuality/attendance & 55.50 & $\begin{array}{l}\text { Can't think of anything/no improvement } \\
\text { needed }\end{array}$ & 45.00 \\
\hline No text provided & 45.50 & Great/excellent commitment/dedication & 25.00 \\
\hline Honesty/trustworthiness & 36.00 & Communication & 21.50 \\
\hline
\end{tabular}




\begin{tabular}{|c|c|c|c|}
\hline \multicolumn{4}{|c|}{ O*NET Job Zone 3} \\
\hline Top five categories (strengths) & $\%$ strengths & Top five categories (AIs) & $\%$ AIs \\
\hline \multicolumn{4}{|c|}{ Registered nurse entry-level } \\
\hline Commitment/dedication/hard worker & 69.00 & Confidence/assertiveness & 52.50 \\
\hline Compassionate/caring & 61.00 & Experience & 52.00 \\
\hline Learning orientation & 49.50 & Great/excellent & 44.50 \\
\hline Dependable/reliable/meets deadlines & 48.00 & Text not provided & 42.00 \\
\hline Attitude/energy & 44.00 & Time management/prioritizing & 34.00 \\
\hline \multicolumn{4}{|c|}{ Registered nurse } \\
\hline Commitment/dedication/hard worker & 61.00 & Text not provided & 51.00 \\
\hline Compassionate/caring & 60.00 & Great/excellent & 49.00 \\
\hline Patient care & 53.00 & Further education/certification & 32.00 \\
\hline Team orientation & 50.00 & Confidence/assertiveness & 28.00 \\
\hline Dependable/reliable/meets deadlines & 42.50 & Knowledge & 26.50 \\
\hline \multicolumn{4}{|c|}{ Sales-field } \\
\hline Commitment/dedication/hard worker & 63.00 & Text not provided & 47.50 \\
\hline Customer service & 52.00 & Great/excellent & 36.50 \\
\hline Building relationships & 42.50 & Knowledge & 22.50 \\
\hline Team orientation & 36.00 & Confidence/assertiveness & 19.50 \\
\hline No text provided & 33.00 & Great/excellent commitment/dedication & 19.00 \\
\hline \multicolumn{4}{|c|}{ Skilled trades worker } \\
\hline Commitment/dedication/hard worker & 70.50 & Text not provided & 54.50 \\
\hline Dependable/reliable/meets deadlines & 55.50 & Great/excellent & 39.00 \\
\hline No text provided & 40.50 & Communication & 24.50 \\
\hline Team orientation & 33.50 & Experience & 18.50 \\
\hline Attention to detail/accuracy & 32.00 & Great/excellent commitment/dedication & 16.50 \\
\hline \multicolumn{4}{|c|}{ Store manager } \\
\hline Commitment/dedication/hard worker & 53.50 & Text not provided & 53.50 \\
\hline Customer service & 51.00 & Great/excellent & 32.00 \\
\hline No text provided & 40.00 & Delegating & 24.50 \\
\hline Communication & 29.50 & Managing others & 19.50 \\
\hline Attention to detail/accuracy & 27.50 & Communication & 18.50 \\
\hline Team orientation & 27.50 & Time management/prioritizing & 18.50 \\
\hline
\end{tabular}




\begin{tabular}{|c|c|c|c|}
\hline \multicolumn{4}{|c|}{ O*NET Job Zone 4} \\
\hline Top five categories (strengths) & $\%$ strengths & Top five categories (AIs) & $\%$ AIs \\
\hline \multicolumn{4}{|c|}{ Accountant } \\
\hline Attention to detail/accuracy & 63.00 & Text not provided & 50.00 \\
\hline Commitment/dedication/hard worker & 59.50 & Great/excellent & 36.00 \\
\hline Dependable/reliable/meets deadlines & 57.00 & Communication & 29.50 \\
\hline Team orientation & 51.50 & Confidence/assertiveness & 27.00 \\
\hline No text provided & 34.00 & Knowledge & 24.00 \\
\hline \multicolumn{4}{|c|}{ Electrical engineer } \\
\hline Commitment/dedication/hard worker & 54.50 & Text not provided & 47.00 \\
\hline Team orientation & 46.00 & Communication & 38.50 \\
\hline Attention to detail/accuracy & 43.50 & Great/excellent & 34.00 \\
\hline Problem solving & 43.50 & Experience & 29.50 \\
\hline Knowledge & 38.50 & Knowledge & 28.50 \\
\hline \multicolumn{4}{|c|}{ Information technology entry-level } \\
\hline Commitment/dedication/hard worker & 69.50 & Text not provided & 51.00 \\
\hline Dependable/reliable/meets deadlines & 45.00 & Great/excellent & 37.50 \\
\hline Learning orientation & 41.00 & Communication & 31.50 \\
\hline Team orientation & 39.50 & Experience & 28.50 \\
\hline Attention to detail/accuracy & 39.00 & Confidence/assertiveness & 25.50 \\
\hline \multicolumn{4}{|c|}{ Project manager } \\
\hline Commitment/dedication/hard worker & 58.00 & Text not provided & 52.50 \\
\hline Communication & 50.50 & Great/excellent & 36.50 \\
\hline Attention to detail/accuracy & 49.50 & Communication & 28.00 \\
\hline Team orientation & 45.50 & Experience & 24.00 \\
\hline Organization skills & 37.00 & Knowledge & 22.50 \\
\hline \multicolumn{4}{|c|}{ Software developer } \\
\hline Commitment/dedication/hard worker & 57.00 & Text not provided & 54.00 \\
\hline Team orientation & 55.50 & Communication & 41.00 \\
\hline Computer/tech skills & 49.50 & Great/excellent & 38.50 \\
\hline No text provided & 39.50 & Computer/tech skills & 30.00 \\
\hline Attention to detail/accuracy & 38.00 & Confidence/assertiveness & 23.50 \\
\hline
\end{tabular}




\begin{tabular}{|c|c|c|c|}
\hline \multicolumn{4}{|c|}{ O*NET Job Zone 5} \\
\hline Top five categories (strengths) & $\%$ strengths & Top five categories (AIs) & $\%$ AIs \\
\hline \multicolumn{4}{|c|}{ Faculty } \\
\hline Commitment/dedication/hard worker & 62.50 & Text not provided & 53.50 \\
\hline Attention to detail/accuracy & 43.00 & Great/excellent & 44.50 \\
\hline Knowledge & 41.50 & Knowledge & 23.00 \\
\hline No text provided & 36.00 & Workaholic/works too much & 18.50 \\
\hline Professionalism & 34.50 & Communication & 18.00 \\
\hline & & Experience & 18.00 \\
\hline \multicolumn{4}{|c|}{ Financial controller } \\
\hline Commitment/dedication/hard worker & 68.00 & Text not provided & 55.50 \\
\hline Attention to detail/accuracy & 59.00 & $\begin{array}{l}\text { Can't think of anything/no improvement } \\
\text { needed }\end{array}$ & 31.50 \\
\hline Team orientation & 45.50 & Communication & 29.00 \\
\hline Knowledge & 37.00 & Great/excellent & 25.00 \\
\hline Integrity & 36.50 & Delegating & 25.00 \\
\hline \multicolumn{4}{|c|}{ Human resources director } \\
\hline Commitment/dedication/hard worker & 44.50 & Text not provided & 44.50 \\
\hline Communication & 42.50 & Great/excellent & 37.50 \\
\hline Adapting to change/flexibility & 39.00 & Work life balance & 26.50 \\
\hline Critical thinking/intelligence & 38.50 & Communication & 22.50 \\
\hline Professionalism & 36.00 & Workaholic/works too much & 20.00 \\
\hline \multicolumn{4}{|c|}{ Nursing manager/director } \\
\hline Commitment/dedication/hard worker & 72.00 & Text not provided & 45.00 \\
\hline Team orientation & 44.00 & Great/excellent & 40.00 \\
\hline Dependable/reliable/meets deadlines & 37.50 & Delegating & 27.00 \\
\hline Communication & 36.50 & Workaholic/works too much & 23.00 \\
\hline Knowledge & 36.50 & Communication & 20.00 \\
\hline \multicolumn{4}{|c|}{ Physician } \\
\hline Commitment/dedication/hard worker & 65.50 & Great/excellent & 51.50 \\
\hline Knowledge & 61.00 & Text not provided & 49.50 \\
\hline Compassionate/caring & 60.00 & $\begin{array}{l}\text { Can't think of anything/no improvement } \\
\text { needed }\end{array}$ & 45.00 \\
\hline Customer service & 55.00 & Communication & 19.50 \\
\hline Team orientation & 40.50 & Knowledge & 19.00 \\
\hline
\end{tabular}

Note. $N=200$ job applicants per survey. \% strengths (work-related strengths) and \% AIs (areas for improvement) $=$ percentage of applicants with at least one reference providing word/short phrase/response pattern. Job Zone 1: occupations that need little or no preparation. Job Zone 2: occupations that need some preparation. Job Zone 3: occupations that need medium preparation. Job Zone 4: occupations that need considerable preparation. Job Zone 5: occupations that need extensive preparation. 